$\begin{array}{lllllll}C & & A & & & \text { E } \\ \text { R } & \text { E } & \text { P } & \text { O } & \text { R } & \text { T }\end{array}$

SW Yeung 楊式穎

Stephen SH Suen 孫錫鴻

Simon $\mathrm{CH} \mathrm{Yu}$ 余俊豪

Terence T Lao 勞子僖

TY Leung 梁德楊

TK Lau 劉子建

\title{
Spontaneous carotid cavernous fistula complicating pregnancy
}

Carotid cavernous fistula is a well-documented but rare condition in pregnancy, about which there are a limited number of reports in the literature. We report such a case in a 41-yearold woman presenting with right-sided headache, proptosis, and diplopia at 37 weeks of gestation. She was subsequently diagnosed to have carotid cavernous fistula based on angiography. Embolisation was performed in the postpartum period. Carotid cavernous fistula has the potential of serious morbidity including visual loss and intracranial haemorrhage. It can be treated effectively by endovascular embolisation, which confers a good prognosis. Although headache is a common complaint during pregnancy, obstetrician should be aware of this condition if the clinical presentation is suspicious.

\section{Case report}

A 41-year-old primigravid woman was referred to the antenatal clinic at 30 weeks of gestation for right-sided headache in April 2009. She had enjoyed good past health without any history of migraine. She complained of on-and-off dull pain over the right temporal region since 27 weeks of gestation. There was no radiation of the pain. The headaches had no particular aggravating or relieving factors, nor was there any other associated neurological symptom or visual disturbance. She had no history of head injury, limb weakness, or convulsions. The blood pressure was 110/69 $\mathrm{mm} \mathrm{Hg}$ and there was no proteinuria. Neurological examination was unremarkable. She was managed as migraine and given simple analgesics. The headache was mild thereafter, until 37 weeks.

She was admitted at $37^{2} / 7$ weeks with a sudden increase in right-sided headache and diplopia for 2 days. The headache was persistent in nature and partially controlled by treatment with paracetamol. The diplopia subsided after rest. She also complained of right-sided retro-orbital pain and pulsating tinnitus.

Physical examination yielded a mild right proptosis, but no chemosis or dilated vessels in the conjunctiva. The blood pressure was normal $(114 / 72 \mathrm{~mm} \mathrm{Hg}$ ) and no proteinuria was detected. Neurological examination (including fundoscopy of both eyes) was normal, as was visual acuity. The symphysis-fundal height corresponded to the gestational age. The fetus was in cephalic presentation and engaged, and the fetal heart rate was normal. Neurological assessment confirmed right-sided proptosis and a bruit was heard over the right orbit. The provisional diagnosis was carotid cavernous fistula (CCF). Plain computed tomography of the brain before delivery revealed a dilated right superior ophthalmic vein and prominent right cavernous sinus (Fig 1). The findings were compatible with the

Key words

Carotid-cavernous sinus fistula; Embolization, therapeutic; Pregnancy

Hong Kong Med J 2013;19:258-61 DOI: $10.12809 / \mathrm{hkmj} 133634$

The Chinese University of Hong Kong, Prince of Wales Hospital, Shatin, Hong Kong. Department of Obstetrics and Gynaecology SW Yeung, MB, ChB, MRCOG SSH Suen, MB, ChB, MRCOC TT Lao, MD, FRCOC TY Leung, MD, FRCOC TK Lau, MD, FRCOG Department of Imaging and Interventional Radiology SCH Yu, MD, FRCR

Correspondence to: Dr SW Yeung Email: clareyeung@cuhk.edu.hk diagnosis of a CCF.

After joint assessment with a neurologist, elective caesarean section was recommended so as to avoid any Valsalva manoeuvre during vaginal delivery, and to allow planned and timed delivery at term to facilitate subsequent investigations and treatment. Uncomplicated lower segment caesarean section was performed at $375 /$, weeks under general anaesthesia, and a healthy baby girl weighing $2.6 \mathrm{~kg}$ was delivered. General anaesthesia was preferred in view of incomplete investigation of the cerebral lesion and uncertain risk of raised intracranial pressure at that juncture.

The patient was transferred to the neurosurgical ward for further management on postoperative day 5 . She recovered well from the caesarean section, but still complained of persistent episodes of right-sided headache without further diplopia. Ophthalmological assessment revealed that the intra-ocular pressure, eye movements, and visual acuity of both eyes were all normal. Digital subtraction angiography was performed on postoperative day 7 , and showed multiple dural arteriovenous fistulae (AVF) connecting branches of the right external carotid artery to the anterior compartment of right cavernous sinus. The AVF also involved the dilated right superior ophthalmic vein and drained into the facial vein (Fig 2). Several small dural AVF were also found to connect the right ophthalmic artery to the right superior ophthalmic vein. 
Embolisation of the CCF was performed 7 weeks after delivery. Selective catheterization of the anterior compartment of the cavernous sinus was successfully achieved through the external jugular vein, retromandibular vein and then via the superior ophthalmic vein using an Excel 14 microcatheter that transcended via a 300-floppy microguidewire. Embolisation was achieved using matrix coils. Complete embolisation was confirmed by arteriography. The entire procedure was uneventful and well-tolerated.

\section{Discussion}

Carotid cavernous fistulae involve one or more abnormal arteriovenous communication between the cavernous sinus and the carotid arterial system. Such lesions can be divided into direct and indirect types based on their anatomy. A direct CCF entails a direct connection between the cavernous segment of the intracavernous carotid artery and the cavernous sinus itself. An indirect (dural) CCF refers to an abnormal connection between the cavernous sinus and the branches of the carotid artery. These lesions can also be classified, based on the aetiology, as traumatic and spontaneous. Traumatic lesions are caused by penetrating head injury or major skull base fractures. Spontaneous ones account for $25 \%$ of all such lesions. ${ }^{1}$ They may represent congenital arteriovenous malformations, which develop spontaneously or in association with atherosclerosis, systemic hypertension, collagen vascular diseases (such as Ehlers-Danlos syndrome), pregnancy, childbirth, and the puerperium. Though uncommon, spontaneous CCFs have been welldocumented in pregnancy, which is reported to be an important precipitating factor. ${ }^{2}$ It was shown that 20 to $30 \%$ of these developed during the latter half of the pregnancy or during delivery. ${ }^{2}$ The mechanism by which CCF ensues during pregnancy is unclear, but it was postulated that arterial hypertension associated with gestation causes pre-existing aneurysms to rupture into the cavernous sinus. ${ }^{2}$ In our patient, however, the blood pressure was normal throughout pregnancy and delivery, so that hypertension cannot be incriminated in this instance.

Clinical presentations include proptosis $(81 \%)$, diplopia $(68 \%)$, cranial bruit $(49 \%)$, retroorbital headache $(34 \%)$, chemosis $(87 \%)$, ocular motor palsies, visual loss, and increased intraocular pressure $(34 \%))^{2,3}$ Theoretically, the symptoms may be aggravated during pregnancy due to the associated haemodynamic and hormonal changes, causing engorgement of the veins. Since our patient had no history of head injury and was previously asymptomatic, the CCF was more than likely de novo. Serious complication like visual impairment affects 60 to $90 \%$ of patients, and can progress if untreated.

\section{妊娠期併發自發性頸動脈海綿狀竇廔管}

頸動脈海綿狀竇廔管雖廣泛報導, 但出現在妊娠期卻是很少見, 文獻 中只有數個報告。本文報告一名41歲女性, 病發時已懷孕 37 週, 她右 邊頭痛、眼球突出及複視。血管造影術顯示病人有頸動脈海綿狀竇廔 管。病人產後接受栓塞術。頸動脈海綿狀竇廔管的後果可以很嚴重, 包括喪失視力及顱內出血。血管內栓塞治療可以有效醫治此症, 且有 好預後。雖然懷孕期內頭痛是很常見的, 但如果臨床症狀有可疑, 產 科醫生應對頸動脈海綿狀竇廔管的可能性提高警覺。

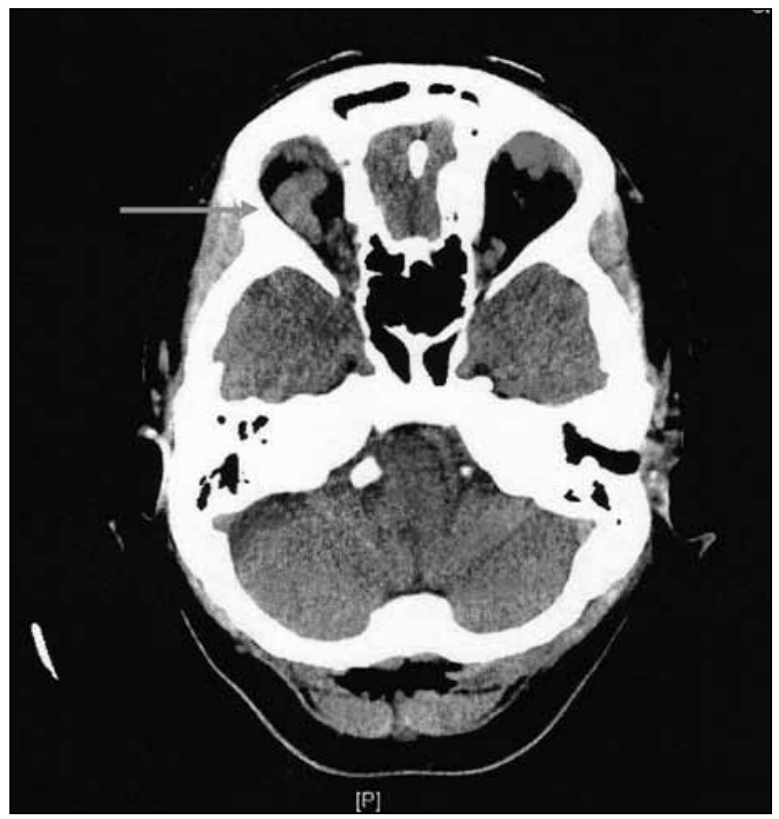

FIG I. Cranial computed tomography shows dilated right superior ophthalmic vein (arrow)

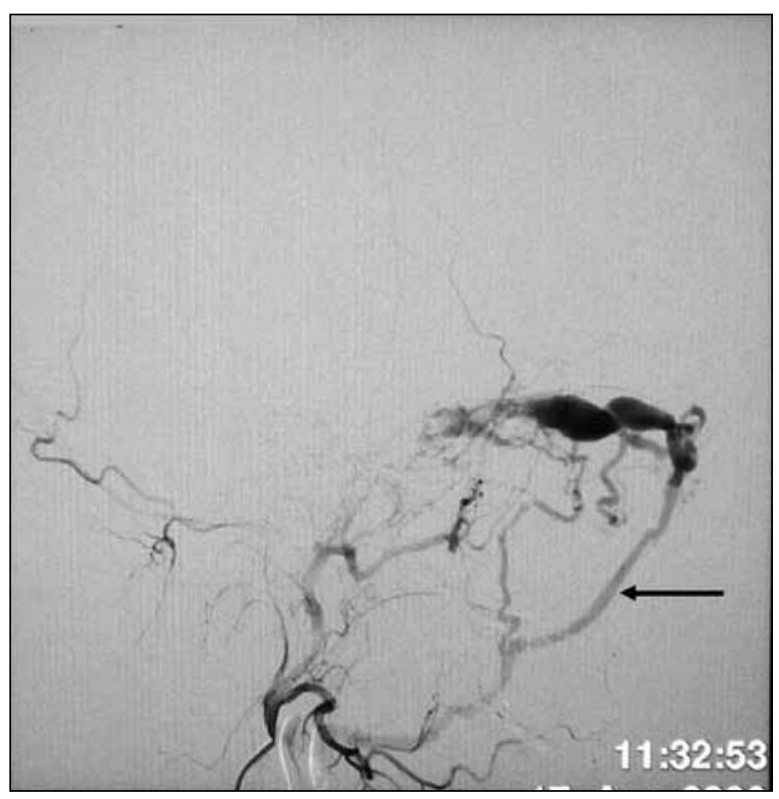

FIG 2. Cerebral angiogram shows reflux of blood flow from the dilated right superior ophthalmic vein into facial vein (arrow) 
Total visual loss has been described in up to $25 \%$ of patients but may be reversible. ${ }^{4}$ Cerebral haemorrhage could occur in 30 to $40 \%$ of patients due to drainage directly into cerebral veins. ${ }^{3}$ Spontaneous intracranial haemorrhage from an occult CCF in pregnancy and puerperium has been reported, and it was stressed that cerebral angiography should be performed to confirm the true disappearance of a CCF. ${ }^{5}$

Carotid cavernous fistula per se has no adverse effect on pregnancy, ${ }^{6}$ but the potentially serious maternal complications like intracranial haemorrhage may cause fetal and maternal morbidity or even mortality. There was no retrograde flow into the cerebral vein in our patient and the blood flow was mainly reflux back into the ophthalmic and facial venous system, for which reason the risk of intracranial haemorrhage was minimal.

Although our patient complained of headache since 27 weeks of gestation, the diagnosis was made at term. Firstly, headache is a common complaint among pregnant women and there were no associated neuro-ophthalmic symptoms or any history of head injury. Thus, a rare condition like CCF is not often suspected. Secondly, even if the diagnosis had been made at 30 weeks, the management would still have been the same apart from the closer monitoring of the symptoms. The timing of treatment should be individualised; definitive treatment before delivery may have to be considered if a complication occurs in mid- or early third trimester, although it may even result in preterm delivery. ${ }^{6}$ In the case reported by Raskind et al, ${ }^{6}$ spontaneous CCF complicating pregnancy was successfully treated by craniotomy and surgical occlusion of the internal carotid artery during the third trimester, but the woman delivered prematurely. Although Meyers et $\mathrm{al}^{7}$ had described the use of endovascular embolisation for treating cerebral artery aneurysms during pregnancy, the use for CCF during pregnancy has not been reported. The commonly expressed concern was the potential fetal abnormalities and the development of childhood cancer due to radiation exposure. We decided to deliver our patient at 37 weeks, because fetal prematurity would not be a concern, and termination of the pregnancy could facilitate maternal management without fetal irradiation during imaging and endovascular embolisation. Concerning the mode of delivery, there was no previous report or study examining the safety of vaginal delivery. For our patient, we recommended caesarean section to avoid the Valsalva manoeuvre which could cause a further increase in intra-ocular pressure ${ }^{8}$ and may cause visual loss. Also labour pain may increase arterial pressure and increase the risk of CCF rupture during vaginal delivery.

The rate of spontaneous resolution of dural fistulae varies from $6 \%$ to $43 \%$. $^{3}$ However, spontaneous improvement of CCFs during or just after pregnancy appears to be rare. ${ }^{9}$ Toya et al ${ }^{10}$ reported such an occurrence in a patient with a dural CCF, which ensued 21 days after an abortion at 12 weeks of gestation. Hirata et $\mathrm{al}^{9}$ described a case of marked regression of a CCF 2 to 3 days after delivery, and speculated that spontaneous improvement in CCF after pregnancy was due to cavernous sinus thrombosis related to changes in blood coagulation that occur during pregnancy and delivery. In our patient, spontaneous improvement of symptoms was not observed. Endovascular embolisation was indicated as the patient had intolerable headache and an audible bruit even weeks after delivery., ${ }^{9,11}$ Barrow et $\mathrm{al}^{11}$ proposed the following as indications for treatment of a spontaneous CCF: (1) visual deterioration; (2) obstructive diplopia related to vascular engorgement and enlargement of the extraocular muscles or neural compression within the cavernous sinus; (3) intolerable bruit or headache; and (4) malignant proptosis with untreatable corneal exposure. In general, the goals of endovascular embolisation were to occlude the retrograde drainage channel to the ophthalmic vein causing ocular symptoms; occlude the retrograde drainage channels to the superficial middle cerebral vein that might cause cerebral venous hypertension and haemorrhage; and obliterate the dural CCF. ${ }^{12}$ In our case, embolisation was performed via transfacial catheterization of the superior ophthalmic vein through the retromandibular vein. This method was recommended by $\mathrm{Yu}$ et $\mathrm{al}^{12,13}$ based on the venographic classification of the dural CCF.

In conclusion, headache is a very common but non-specific complaint in pregnancy. Carotid cavernous fistula may present simply with headache in the absence of other symptoms. Without a high index of suspicion, the diagnosis can be delayed or missed. Meticulous clinical and radiological evaluations are crucial in making an accurate diagnosis. ${ }^{3}$ A correct diagnosis is important, as a CCF could be associated with serious maternal complications such as blindness and intracranial haemorrhage.

\section{References}

1. Das JK, Medhi J, Bhattacharya P, et al. Clinical spectrum of spontaneous carotid-cavernous fistula. Indian J Ophthalmol 2007;55:310-2. cross ref

2. Walker AE, Allegre GE. Carotid-cavernous fistulas. Surgery
1956;39:411-22.

3. Meyers PM, Halbach VV, Dowd CF, et al. Dural carotid cavernous fistula: definitive endovascular management and long-term follow-up. Am J Ophthalmol 2002;134:85- 
92. cross ref

4. Naesens R, Mestdagh C, Breemersch M, Defreyne L. Direct carotid-cavernous fistula: a case report and review of the literature. Bull Soc Belge Ophtalmol 2006;(299):43-54.

5. Lin TK, Chang CN, Wai YY. Spontaneous intracerebral hematoma from occult carotid-cavernous fistula during pregnancy and puerperium. Case report. J Neurosurg 1992;76:714-7. cross ref

6. Raskind R, Johnson N, Hance D. Carotid cavernous fistula in pregnancy. Angiology 1977;28:671-6. cross ref

7. Meyers PM, Halbach VV, Malek AM, et al. Endovascular treatment of cerebral artery aneurysms during pregnancy: report of three cases. AJNR Am J Neuroradiol 2000;21:130611.

8. Lawrence MS. Effects of bending, lifting and valsalva maneuver on intraocular pressure. Invest Ophthalmol Vis Sci 2003;44(Suppl):E-Abstract 1297.

9. Hirata $Y$, Matsukado $Y$, Takeshima H, Seto H. Postpartum regression of a spontaneous carotid-cavernous fistula-case report. Neurol Med Chir (Tokyo) 1988;28:673-6. cross ref

10. Toya S, Shiobara R, Izumi J, Shinomiya Y, Shiga H, Kimura C. Spontaneous carotid-cavernous fistula during pregnancy or in the postpartum stage. Report of two cases. J Neurosurg 1981;54:252-6. cross ref

11. Barrow DL, Spector RH, Braun IF, Landman JA, Tindall SC, Tindall GT. Classification and treatment of spontaneous carotid-cavernous sinus fistulas. J Neurosurg 1985;62:24856. cross ref

12. Yu SC, Cheng HK, Wong GK, Chan CM, Cheung JY, Poon WS. Transvenous embolization of dural carotid-cavernous fistulae with transfacial catheterization through the superior ophthalmic vein. Neurosurgery 2007;60:1032-7; discussion 1037-8. cross ref

13. Yu SC, Cheng KM, Tam PH, et al. A venographic operational classification for transvenous embolization of dural carotidcavernous fistula. Neuroradiology 2011;53:993-9. cross ref 